\title{
PRIMEIROS SOCORROS: INVESTIGAÇÃO DO TREINAMENTO DE PROFESSORES DE UMA ESCOLA DA REDE PÚBLICA DE CAMPO GRANDE
}

\section{FIRST AID: INVESTIGATING THE TRAINING OF TEACHERS AT A PUBLIC SCHOOL IN CAMPO GRANDE}

\section{PRIMEROS AUXILIOS: ESTUDIAR LA CAPACITACION DE LOS PROFESORES EN UNA ESCUELA PÚBLICA EN CAMPO GRANDE}

\author{
Bruno Aguirre ${ }^{1}$, Daniel Bueno Ricardo ${ }^{2}$, Ursulla Vilella Andrade ${ }^{3}$
}

Como citar esse artigo: Aguirre B, Ricardo DB, Andrade UV. Primeiros Socorros: investigação do treinamento de professores de uma escola da rede pública de Campo Grande. Rev Enferm Atenção Saúde [Internet]. 2021 [acesso em:__]; 10(3):e202126. doi: https://doi.org/ 10.18554/reas.v10i3.4778

\section{RESUMO}

Introdução: Qualquer pessoa pode passar por situações de urgência e emergência, em qualquer lugar. Dessa forma, a primeira pessoa a se deparar com a cena deve ser o primeiro a prestar socorros. Objetivo: identificar o conhecimento em primeiros socorros de professores de uma escola municipal. Método: Estudo de caráter exploratório, quantitativo realizado com professores de uma escola municipal de Campo Grande. A amostra foi composta por 43\% $(n=30)$ dos professores. Foi realizado a aplicação de um questionário após treinamento de primeiros socorros. Resultados e discussão: Quando questionados sobre os números de emergência, 43,4\% (n=13) conheciam. Em relação a abertura de vias aéreas, 46,6\% $(n=14)$ responderam corretamente. Posicionamento da vítima para compressão cardíaca foi assinalado assertivamente por 53,4\% $(\mathrm{n}=16)$. Conclusão: Mesmo após receberem treinamentos, grande parte dos professores ainda não se demonstraram preparados a prestar assistência de urgência ou emergência. O profissional capacitado para responder esta demanda seria o enfermeiro.

Descritores: Socorro de Urgência; Educação em Saúde; Primeiros Socorros.

\footnotetext{
${ }^{1}$ Graduação em Enfermagem pela Universidade Católica Dom Bosco, Campo Grande-MS.

${ }^{2}$ Graduação em Enfermagem pela Universidade Católica Dom Bosco, Campo Grande-MS.

${ }^{3}$ Graduação em enfermagem pela Universidade Estadual de Santa Cruz (2009) e mestrado em Doenças Infecciosas e Parasitárias pela Universidade Federal de Mato Grosso do Sul (2014). Especialista em Saúde Pública e Acupuntura - medicina tradicional chinesa. Professora da Universidade Católica Dom Bosco, Campo Grande-MS.
} 


\begin{abstract}
Introduction: Anyone can go through urgent and emergency situations, anywhere. Thus, the first person to come across the scene must be the first to provide assistance. Objective: to identify first aid knowledge of teachers at a municipal school. Method: An exploratory, quantitative study carried out with teachers from a municipal school in Campo Grande - MS. The sample was composed of $43 \%(n=30)$ of teachers. A questionnaire was administered after first aid training. Results and discussion: When asked about the emergency numbers, 43.4\% ( $n=13$ ) knew about it. Regarding the opening of the airways, 46.6\% $(n=14)$ responded correctly. Positioning the victim for cardiac compression was assertively reported by $53.4 \%(n=16)$. Conclusion: Even after receiving training, most teachers have not yet shown themselves prepared to provide urgent or emergency assistance. The professional trained to answer this demand would be the nurse.
\end{abstract}

Descriptors: Emergency Relief; Health education; First aid.

\title{
RESUMEN
}

Introducción: Cualquiera puede pasar por situaciones urgentes y de emergencia, en cualquier lugar. Por lo tanto, la primera persona que se encuentre con la escena debe ser la primera en brindar asistencia. Objetivo: Identificar el conocimiento de primeros auxilios que tienen los maestros de una escuela municipal. Método: Estudio exploratorio cuantitativo realizado con docentes de una escuela municipal de Campo Grande, MS. La muestra estuvo compuesta por el 43\% ( $\mathrm{n}=30)$ de los docentes. Se administró un cuestionario después del entrenamiento de primeros auxilios. Resultados y discusión: Cuando se les preguntó los números de emergencia, el 43,4\% (n=13) los sabía. En cuanto a la apertura de las vías aéreas, el 46,6\% $(n=14)$ respondió correctamente. La posición de la víctima para la compresión cardíaca fue marcada asertivamente por el 53,4\% $(n=16)$. Conclusión: Incluso después de recibir la capacitación, la mayoría de los docentes aún no está preparado para brindar asistencia de urgencia o de emergencia. El profesional capacitado para responder a esta demanda sería el enfermero.

Descriptores: Ayuda de emergencia; Educación para la Salud; Primeros Auxilios.

\section{INTRODUÇÃO}

A educação em saúde está diretamente ligada ao senso de cidadania, solidariedade e responsabilidade do indivíduo dentro do meio ao qual pertence, tornando-se uma ferramenta na promoção e prevenção a saúde em eventos emergenciais. A carência de preparo do grupo escolar impede o socorro no momento do incidente, como a situação de pânico ao ver o acidentado pode ocorrer a manipulação incorreta da vítima e ainda a solicitação excessiva, às vezes desnecessárias do socorro especializado em emergência. ${ }^{1}$

A educação em saúde da população apesar de negligenciada no modelo de saúde atual do Brasil, tem papel extremamente importante para a redução da morbimortalidade nos diversos casos de acidentes e mal súbitos que possam ser encontrados no cotidiano, facilitando $\mathrm{o}$ fluxo de atendimento pré-hospitalar, tal como na sobrevivência da vítima. Somando-se a isso uma estratégia para atendimento emergencial dentro da escola 
seria a presença de um enfermeiro, profissional mais capacitado para este atendimento. Um exemplo é que isto já ocorre em países desenvolvidos. ${ }^{1}$

Primeiros socorros referem-se ao primeiro atendimento que se presta à pessoa que está ferida ou adoece repentinamente. Considera-se fundamental que todos tenham acesso às informações sobre os principais acidentes, como preveni-los e como agir diante das situações que exigem cuidados imediatos a fim de minimizar complicações decorrentes de medidas intempestivas e inadequadas. $^{2}$

Os professores são potenciais testemunhas, que necessitam realizar os primeiros socorros em casos de acidentes na escola, entretanto, apesar de participarem de cursos sobre o tema, estes profissionais adotam condutas incorretas diante de situações de acidente. ${ }^{3}$

Culturalmente as preocupações com às questões de segurança dentro do ambiente escolar, estão voltadas quase exclusivamente com a violência. Entretanto, características como imaturidade física e mental, inexperiência, curiosidade, tendência a imitar comportamentos adultos, falta de noção corporal ou de coordenação motora, somado a existência de rampas de acesso inadequadas, fiações expostas, azulejos quebrados, ausência de placas de sinalização e de rotas de fuga e alarmes, botijões de gás expostos ou mal instalados, encanamentos e tomadas distribuídos ao alcance das crianças, promovem situações mais perigosas do que a própria violência em si. ${ }^{4}$

De acordo com algumas entidades representativas, como a American Heart Association, a principal causa da morte pré-hospitalar é a falta de atendimento e a segunda é o socorro inadequado. Caso em algum incidente onde a vítima evolua para uma parada cardiorrespiratória, se a reanimação cardiopulmonar (RCP) for realizada ainda no primeiro minuto, as chances de sucesso são de até $98 \%$. A partir do quinto minuto, as chances de sucesso caem para $25 \%$ e, se a RCP for executada após dez minutos, a chance de a vítima sobreviver cai para $1 \%{ }^{6}$

Nesse sentido é válido ressaltar o compromisso e a responsabilidade que a instituição tem pelo que acontece aos alunos quando estão no ambiente escolar. Torna-se essencial que os educadores, que são a população que mantém contato com os alunos, estejam capacitados a agir frente às situações que exijam cuidados imediatos, a fim de evitar maiores complicações à saúde dos seus alunos e honrar o compromisso com os pais. ${ }^{7}$

Baseando-se nas prerrogativas do ensino em saúde para leigos, este 
trabalho teve como objetivo de identificar o conhecimento em primeiros socorros de professores de uma escola municipal.

\section{MÉTODOS}

Foi realizado um estudo de caráter exploratório-quantitativo com os professores de uma escola municipal situada na cidade de Campo Grande - MS. Ela foi escolhida por se tratar de um bairro carente e conhecidamente violento. A escola atende alunos do ensino fundamental. Foi realizada a aplicação de um questionário após treinamento de primeiros socorros oferecido pelo município, com o intuito de identificar se o treinamento realizado teve eficácia em ensinar e aprimorar o conhecimento prévio ou nulo da população alvo sobre o tema proposto.

O instrumento de coleta foi adaptado a partir de um estudo realizado por Flávia Sell ${ }^{8}$, que avalia os conhecimentos dos profissionais de educação física em relação à primeiros socorros e situações de urgência e emergência. Foram selecionadas as questões que melhor se adaptaram a proposta da pesquisa. Os questionários foram aplicados em 2019, com as devidas autorizações emitidas pela Secretaria de Educação do Município e aceite individual de cada participante, onde foi explicado brevemente os objetivos da pesquisa e os Rev Enferm Atenção Saúde [Online]. Out/Dez 2021; 10(3):e202126 termos de não exposição da identidade dos participantes em qualquer parte do trabalho.

Os critérios para inclusão dos participantes foram: terem recebido ou participado de qualquer tipo de capacitação de primeiros socorros, estarem ativos na escola, terem concordado em participar da pesquisa através do termo de consentimento livre e esclarecido (TCLE). Foram excluídos professores que se encontravam de licença médica, férias ou folga.

O presente estudo foi composto por 30 professores, 10 homens e 20 mulheres, que corresponde a aproximadamente $42,9 \%$ dos professores da escola. Para a avaliação das condutas frente às situações de urgência e emergência, o questionário abrange algumas das intercorrências mais comuns relacionadas ao âmbito escolar. As respostas foram analisadas e classificadas em corretas, incorretas e sem respostas.

Os dados foram transcritos em uma planilha Excel®, descritos em número, em porcentagens e representados em gráficos. O projeto foi aprovado pelo Comitê de Ética em Pesquisa da Universidade Católica Dom Bosco, sob o número de CAAE: 09677319.4.0000.5162, de acordo com as exigências da resolução $n^{\circ} 466 / 2012$ do Conselho Nacional de 
Saúde/MS, que trata de pesquisas envolvendo seres humanos.

\section{RESULTADOS}

De acordo com a plataforma Datasus, ocorreram 594 óbitos por causas externas evitáveis no município de Campo Grande - MS entre os anos de 2010 a 2017 na faixa etária média escolar, de 5 a 19 anos, óbitos que ocorreram em vias públicas, ambiente domiciliar e outros, excluindo óbitos ocorridos em unidades de saúde e/ou hospitais. ${ }^{9}$

Segundo a Lei $\mathrm{n}^{\circ} 13.722$ de 4 de outubro de 2018, “Torna-se obrigatória a capacitação em noções básicas de primeiros socorros de professores e funcionários de estabelecimentos de ensino públicos e privados de educação básica e de estabelecimentos de recreação infantil", mais bem especificadas nos artigos $1^{\circ}$ e $2^{\circ}$ desta mesma lei. Assim colocando o ensino do Suporte Básico de Vida e Primeiros Socorros em caráter de obrigatoriedade no ensino para todos os profissionais relacionados a educação infanto-juvenil. ${ }^{10}$

Baseando-se nessas prerrogativas, foi realizada a investigação proposta, obtendo-se os seguintes resultados:

Tabela 1. Conhecimento dos professores a respeito da quantidade dos números de emergências. $(n=30)$.

\begin{tabular}{lcccc}
\hline \multirow{2}{*}{ RESPOSTAS } & \multicolumn{3}{c}{ PROFESSORES DA REDE PUBLICA\% (n) } \\
\cline { 2 - 5 } & TODOS APENAS 2 & APENAS 1 & $\begin{array}{c}\text { NAO } \\
\text { RESPONDEU }\end{array}$ \\
\hline $\begin{array}{l}\text { Conhecimento dos } \\
\text { Número de Emergência } \\
\text { (SAMU, BOMBEIROS }\end{array}$ & $43,4 \%(13)$ & $26,7 \%(8)$ & $16,7 \%(5)$ & $13,2 \%(4)$ \\
E POLÍCIA) & & & & \\
\hline
\end{tabular}

Elaborada pelos autores

Pode-se observar a quantidade de professores que não sabem corretamente os números de socorro para vítimas de qualquer natureza, o que é preocupante, pois mesmo sem a realização de um treinamento, seria interessante ter conhecimento desses telefones para chamar o socorro se por acaso, presenciar Rev Enferm Atenção Saúde [Online]. Out/Dez 2021; 10(3):e202126 alguma ocorrência que precise de alguma equipe de transporte de saúde. Já na tabela 2 podemos observar os acertos obtidos nas questões do estudo, como pode ser verificado abaixo. Os participantes da pesquisa se enquadram em três opções: os que responderam corretamente, os que responderam de maneira incorreta e o que 
não responderam ao questionário de

múltipla escolha.

Tabela 2. Acertos obtidos em relação as questões respondidas pelos professores participantes. Junho de 2019. Campo Grande - MS. (n=30).

\begin{tabular}{|c|c|c|c|}
\hline \multirow{2}{*}{ RESPOSTAS } & \multicolumn{3}{|c|}{$\begin{array}{c}\text { PROFESSORES DA REDE PUBLICA } \\
\%(\text { (n) }\end{array}$} \\
\hline & $\begin{array}{c}\text { RESPONDEU } \\
\text { CORRETAMENTE }\end{array}$ & INCORRETO & NAO RESPONDEU \\
\hline $\begin{array}{l}\text { Julgamento da necessidade de } \\
\text { realizar os primeiros Socorros? }\end{array}$ & $53,4 \%(16)$ & $43,3 \%(13)$ & $3,3 \%(1)$ \\
\hline $\begin{array}{c}\text { Quais os detalhes mais importantes } \\
\text { a serem observados? }\end{array}$ & $66,7 \%(20)$ & $33,3 \%(10)$ & 0 \\
\hline $\begin{array}{c}\text { Quando uma pessoa estiver } \\
\text { convulsionando, o que devo fazer? }\end{array}$ & $60 \%(18)$ & $33,3 \%(10)$ & $6,7 \%(2)$ \\
\hline $\begin{array}{l}\text { Como verificar se a vítima está } \\
\text { respirando? }\end{array}$ & $83,3 \%(25)$ & $6,7 \%(2)$ & $10 \%(3)$ \\
\hline $\begin{array}{l}\text { Como realizar manobra de } \\
\text { abertura de via aérea? }\end{array}$ & $46,6 \%(14)$ & $53,4 \%(16)$ & 0 \\
\hline $\begin{array}{l}\text { Qual posição para realizar a } \\
\text { massagem cardíaca? }\end{array}$ & $53,4 \%(16)$ & $43,3 \%(13)$ & $3,3 \%(1)$ \\
\hline $\begin{array}{l}\text { Qual é o local do corpo adequado } \\
\text { para realizar a massagem } \\
\text { cardíaca? }\end{array}$ & $43,3 \%(13)$ & $56,7 \%(17)$ & 0 \\
\hline $\begin{array}{l}\text { Como proceder em caso de } \\
\text { suspeita de fratura? }\end{array}$ & $50 \%(15)$ & $50 \%(15)$ & 0 \\
\hline $\begin{array}{l}\text { Como proceder em caso de } \\
\text { suspeita de fratura na coluna } \\
\text { cervical? }\end{array}$ & $70 \%(21)$ & $30(9)$ & 0 \\
\hline $\begin{array}{c}\text { Como proceder diante de } \\
\text { hemorragias? }\end{array}$ & $53,4 \%(16)$ & $46,6 \%(14)$ & 0 \\
\hline \multicolumn{4}{|l|}{ Elaborada pelos autores } \\
\hline \multicolumn{2}{|c|}{$\begin{array}{r}\text { Observou-se nesta tabela } 2 \text { a } \\
\text { quantidade de professores que não sabem a }\end{array}$} & \multicolumn{2}{|c|}{$\begin{array}{l}\text { aéreas em vítimas sem suspeita de lesão } \\
\text { cervical, } 14 \quad(47 \%) \text { participantes } \\
\text { responderam corretamente, } 12(40 \%) \\
\text { responderam incorretamente e } 4(13 \%) \text { não } \\
\text { responderam ou não sabiam. E sobre a } \\
\text { posicionamento da vítima para realizar } \\
\text { massagem cardíaca, } 15(50 \%) \text { participantes }\end{array}$} \\
\hline
\end{tabular}


responderam corretamente, $11 \quad(37 \%)$ responderam incorretamente e 4 (13\%) não responderam ou não sabiam.

\section{DISCUSSÃO}

Neste estudo foi identificado que mesmo após treinamentos recebidos, grande parte da população participante não apresenta respaldo de conhecimento mínimo para serem considerados aptos para agir de forma benéfica em emergências. Dos dados adquiridos podese notar que apenas $43,4 \%$ dos participantes sabe corretamente todos os números de emergência, resultado esse que demonstrou-se insatisfatório, visto que solicitar socorro especializado comunicando a provável causa do quadro presenciado, o número de vítimas, a gravidade das mesmas e outras informações relevantes, é uma das fases mais importantes durante o atendimento ao acidentado, uma vez que o acionamento dos serviços de emergência em tempo hábil, garante o atendimento profissional precoce, aumentando as chances de sobrevivência da vítima e diminuindo as chances de sequela.

O professor da educação infantil é um agente de mudanças que quando realizado treinamento, pode opinar sobre primeiros socorros, que porventura, é um assunto principal da enfermagem. É de extrema relevância que ele possua conhecimentos sobre os principais acidentes que ocorrem na instituição de ensino quando não se tem a presença de um enfermeiro ou bombeiro civil para estar prestando o atendimento especializado, assim como deve ter segurança e se sentir preparado para saber lidar em situações de emergência, sendo a ligação principal entre os alunos. ${ }^{11}$

Sobre a convulsão, $60 \%$ dos professores souberam a resposta correta em qual atitude tomar ao se presenciar uma crise convulsiva. As crises convulsivas decorrentes de pessoas epiléticas ou não, ainda não são bem esclarecidas, em relação a quais condutas devem ser tomadas, onde a população ainda apresenta crenças e mitos que são amplamente repetidos na sociedade. No Brasil poucos são os dados referentes a epilepsia e crises convulsivas no, mas um levantamento feito nas cidades de Campinas e São José dos Campos, no estado de São Paulo, segundo o qual a prevalência de epilepsia ativa - com algum episódio de crise nos últimos 24 meses por faixa etária foi de 2,3/1.000 para crianças até 4 anos, 4,3/1.000 para crianças entre 5 e 9 anos, 3,8/1.000 para quem tem entre 10 e 19 anos, 5,8/1.000 para pessoas entre 20 e 59 anos e 8,5/1.000 para pessoas com 60 anos ou mais ${ }^{12}$, demonstrando a necessidade da desmistificação e elucidação das condutas corretas a respeito deste tema. 
Em relação aos questionamentos referentes a identificação dos sinais vitais, $66,7 \%$ dos participantes sabem quais são os principais pontos a se identificar e repassar para os serviços de emergência, ao se deparar com uma vítima inconsciente, enquanto $83,3 \%$ sabem as técnicas básicas para identificar se o acidentado mantém a capacidade respiratória. Identificar se um indivíduo inconsciente está respirando é fundamental para reconhecer a possibilidade de uma parada cardiorrespiratória $(\mathrm{PCR})^{13}$, sendo uma das informações fundamentais a se repassar aos serviços de urgência e emergência.

Já em relação a manutenção da abertura de vias aéreas em vítimas ao qual não possuam suspeita de lesão na coluna vertebral, apenas 46,6\% dos professores demonstraram conhecimento da técnica correta. Cabe ressaltar que a queda da língua é uma das causas mais comuns de obstrução de vias aéreas em vítimas inconscientes, e que a técnica de elevação do queixo permite a abertura dessas vias. ${ }^{14}$ Porém, segundo os dados, a maioria dos participantes, não souberam especificar a execução correta desta técnica.

No que se trata ao correto posicionamento da vítima para a realização da técnica de ressuscitação cardiopulmonar, 53,4\% dos professores responderam de forma adequada, já em relação a posição anatômica adequada para a execução da RCP, apenas 43,3\% responderam que esta deve ser realizada na região central do esterno "na altura dos mamilos", ou seja, dois dedos acima do apêndice xifoide. A realização do RCP em uma vítima em PCR, ainda que por apenas compressões torácicas no atendimento préhospitalar, contribui sensivelmente para o aumento das taxas de sobrevivência. ${ }^{15}$

Em relação a cuidados mínimos em vítimas de possível trauma ou lesão em coluna vertebral, apenas $47 \%$ dos participantes respondeu de forma correta, enquanto $40 \%$ apresentaram resposta inadequadas e que podem ser fatais a vítima traumática. Ao observar-se a origem dos acidentes em ambiente escolar, o desconhecimento das técnicas mínimas de imobilização de vítima de possível trauma, associados a falta de conhecimento ou preparo emocional para o atendimento, torna o socorrista leigo um fator de risco para vítima.

No Brasil, as internações decorrentes de lesões na coluna correspondem a $0,2 \%$ dos traumas (SIH/SUS). A coluna cervical é a segunda mais comumente lesada (28\%), precedida pela junção lombo-sacra (60\%). Os traumas no nível cervical, entretanto, são os maiores responsáveis por lesão medular $(45,8 \%) .{ }^{16}$ Observando o índice dividido de acertos em relação a este assunto, 
denota-se a falta de conhecimento embasado para a garantia de cuidados adequados no atendimento, o que acaba ferindo o princípio de não-maleficência, preconizado pela bioética ao se prestar atendimento a vítima.

Em relação às condutas em caso de suspeita de fraturas, 50\% dos participantes responderam de maneira adequada aos cuidados realizados. A maioria dos leigos não conhece os procedimentos básicos no cuidado do paciente em caso ou suspeita de fratura, como a retirada de anéis, pulseiras, relógios ou qualquer que possam interferir na circulação do membro afetado, e logo após proceder com a imobilização do membro, respeitando a cinemática da fratura, não tracionando, empurrando ou mesmo tentando colocá-lo "no lugar correto". ${ }^{17}$

Já sobre hemorragias, 53,4\% dos participantes responderam de forma correta as condutas mínimas. Das ações a serem realizadas em caso de hemorragia, que são ressaltadas para uso mesmo para leigos, em caso de lesão em membros superiores ou inferiores, são a compressão direta no ferimento com o uso de gazes ou pano limpo, manter a criança calma e acordada e entrar em contato com os pais. Em hemorragias nasais, deve-se abaixar a cabeça da criança com o tronco inclinado para frente; comprimir a narina que sangra com os dedos; aplicar gelo ou compressas frias; não assoar. Caso o sangramento não cesse, deve-se colocar um tampão, de algodão ou gazes, de maneira a preencher bem a cavidade nasal. ${ }^{18}$

O atual modelo de saúde tem como uma de suas estratégias de ação a disseminação do conhecimento em saúde na sociedade, ao se observar esta estratégia no ambiente escolar, em um quesito de exposição a riscos, torna-se necessário junto ao ensino regular das técnicas de primeiros socorros, o estabelecimento de estratégias para garantir não só a fixação deste conhecimento, mas também a segurança e habilidades necessárias para reagir de forma adequada a um socorrista, mesmo que leigo, mas detentor de conhecimentos e respaldado para cenas emergenciais que ele possa vir a encontrar.

A garantia na qualidade da assimilação do conhecimento ministrado, assegura que o professor ante situação emergencial, tenha autonomia e respaldo para agir de forma segura e garantir um atendimento de primeiros socorros de qualidade, capaz de gerar a sobrevivência da vítima e minimizar as possíveis sequelas.

Dessa forma, é clara a necessidade da disseminação dos conhecimentos em saúde como fator determinante da melhoria no atendimento em modo geral, reafirmados no 
atendimento precoce e acompanhamento do quadro clínico da vítima desde os primeiros momentos da ocorrência.

\section{CONCLUSÃO}

Pelos resultados obtidos foi possível sugerir que mesmo após receberem treinamentos em primeiros socorros, grande parte dos professores ainda não se demonstram aptos a prestarem assistência em casos de urgência ou emergência, não demonstrando conhecimento mínimo sobre os cuidados com a vítima, sinais vitais e técnicas básicas de ressuscitação cardiopulmonar ou mesmo conhecimento dos números de emergência.

É necessário a mudança na visão de obrigatoriedade no conhecimento em saúde, focando na importância e impacto que estes conhecimentos possuem em situações emergenciais e no cotidiano das pessoas. Faz-se necessário um profissional enfermeiro no âmbito escolar, preparado para atuar em qualquer caso de emergência; em países desenvolvidos, isso já ocorre.

No que tange as limitações encontradas pelo estudo, reporta-se ao fato de apenas uma escola ter participado do estudo e o curto espaço de tempo para aplicação de pré e pós teste.

\section{REFERÊNCIAS}

1. Tinoco VA, Reis MMT, Freitas LN. O enfermeiro promovendo saúde como educador escolar: atuando em primeiros socorros. Rev Transformar [Internet]. 2014 [citado em 16 out 2018]; 1(6):104-13. Disponível em: http://www.fsj.edu.br/transformar/index.ph $\mathrm{p} /$ transformar/article/view/16/15

2. Pereira CK, Paulino JR, Saltarelli RMF, Carvalho AMP, Santos RB, Silveira TVL, et al. A construção de conhecimentos sobre prevenção de acidentes e primeiros socorros junto ao público leigo. Rev Enferm Cent-Oeste Min. [Internet]. jan/abr 2015 [citado em 16 out 2018]; 5(1):147885. Disponível em:

http://www.seer.ufsj.edu.br/index.php/reco $\mathrm{m} /$ article/view/456/837

3. Galindo Neto NM, Carvalho GCN, Castro RCMB, Caetano JA, Santos ECB, Silva TM, et al. Teachers' experiences about first aid at school. Rev Bras Enferm. [Internet]. 2018 [citado em 16 out 2018]; 71(Suppl 4):1678-84. Disponível em: https://www.scielo.br/j/reben/a/4KrgL3dM BNXwGnBmdPjZSNJ/?format=pdf\&lang $=$ en

4. Conti KLM, Zanatta SC. Acidentes no ambiente escolar: uma discussão necessária. In: Secretaria de Educação (Paraná). Os desafios da escola pública paranaense na perspectiva do professor PDE [Internet]. Curitiba: Secretaria de Educação; 2014 [citado em 04 out 2021]. (Cadernos PDE, v. 1). Disponível em: http://www.diaadiaeducacao.pr.gov.br/port als/cadernospde/pdebusca/producoes_pde/ 2014/2014_unesparparanavai_cien_artigo_ kesia_liriam_meneguel.pdf

5. Taddeo PS, Gomes KWL, Caprara A, Gomes AMA, Oliveira GC, Moreira TMM. Prática educativa e empoderamento de pacientes com doenças crônicas. Ciênc Saúde Colet. [Internet]. nov 2012 [citado em 23 dez 2021]; 17(11):2923-30.

Disponível em:

https://www.scielo.br/j/csc/a/5Cg33mMfQ V3VWTJxJ7DcBfG/?format=pdf\&lang=pt 
6. Del Vecchio FB, Del Vecchio AHM, Blanco BFV, Gonçalves A. Formação em primeiros socorros: estudo de intervenção no âmbito escolar. Cad Form RBCE [Internet]. 2010 [citado em $23 \mathrm{dez} 2021$ ]; 1(2):56-70. Disponível em:

http://revista.cbce.org.br/index.php/cadern os/article/view/983/555

7. Leite ACQB, de Freitas GB, de Mesquita MML, de França RRF, Fernandes SCA. Primeiros socorros nas escolas. Revista Extendere. Rio Grande do Norte. 2013[citado em 16 out 2018]; 2(1):61 - 70. Disponível em: https://proex.uern.br/default.asp?item=proe $\mathrm{X}$-revistaextendere.

8. Dal-Bó HQ. Avaliação do nível de conhecimento dos profissionais de educação física em possíveis situações emergenciais durante o exercício físico [Internet]. [Trabalho de Conclusão de Curso]. Florianopólis, SC: Universidade Federal de Santa Catarina; 2013. [citado em 08 jun 2019]. Disponível em: https://repositorio.ufsc.br/bitstream/handle/ 123456789/103743/TCC_HENRIQUE\%2 0DE\%20QUADRA\%20DALB\%C3\%93.pdf? sequence $=1 \&$ isAllowed $=y$ 9. Ministério da Saúde (Brasil). DATASUS: informações de Saúde, Epidemiológicas e Morbidade: banco de dados [Internet]. Disponível em: http://tabnet.datasus.gov.br/cgi/tabcgi.exe? sim/cnv/evitb10ms.def\%20gt. Acesso em: 08 jun. 2019.

10. Presidência da República (Brasil). Lei n.13.722, de 4 de outubro de 2018. Torna obrigatória a capacitação em noções básicas de primeiros socorros de professores e funcionários de estabelecimentos de ensino públicos e privados de educação básica e de estabelecimentos de recreação infantil [Internet]. Diário Oficial da União, Brasília, 5 out 2018 [citado em 23 dez 2021]. Disponível em:

http://www.planalto.gov.br/ccivil_03/_ato2 015-2018/2018/lei/L13722.htm

11. Siebeneichler AEM, Hahn GV. Professores da pré-escola e o agir em situações de emergência. Rev Destaques Acadêmicos [Internet]. 2014 [citado em 23 dez 2021]; 6(3):139-47. Disponível em: http://www.univates.br/revistas/index.php/ destaques/article/view/424/416

12. Cunha RB. O conhecimento do público acerca da epilepsia: uma pequena amostragem em Campinas (SP). BIS, Bol Inst Saúde [Internet]. 2011 [citado em 23 dez 2021]; 13(2):147-55. Disponível em: https://periodicos.saude.sp.gov.br/index.ph p/bis/article/view/33676/32496

13. Chehuen Neto JA, Brum IV, Pereira DR, Santos LG, Moraes SL, Ferreira RE. Conhecimento e interesse sobre suporte básico de vida entre leigos. Int J

Cardiovasc Sci. [Internet]. 2016 [citado em 23 dez 2021]; 29(6):443-52. Disponível em:

http://www.onlineijcs.org/sumario/29/pdf/ v29n6a04.pdf

14. Pergola AM, Araujo IEM. O leigo e o suporte básico de vida. Rev. Esc. Enferm. USP [Internet]. 2009 [citado em $23 \mathrm{dez}$ 2021]; 43(2):335-42. Disponível em: https://www.scielo.br/j/reeusp/a/NZRG6Ph ngJFqwtnrPy4pTNQ/?format=pdf\&lang=p $\mathrm{t}$

15. Gonzalez MM, Timerman S, GianottoOliveira R, Polastri TF, Canesin

F,Schimidt A, et al. I Diretriz de ressuscitação cardiopulmonar e cuidados cardiovasculares de emergência da Sociedade Brasileira de Cardiologia. Arq Bras Cardiol. [Internet]. ago 2013 [citado em 14 jun 2021]; 101(2 Supl 3):3-174. Disponível em: https://www.scielo.br/j/abc/a/FzpcTtwTdpf 8DDBYMS7vprr/?format=pdf\&lang=pt 16. Azevedo LP, Ribeiro LC, Teixeira LRM, Barbosa LBS, Guimarães MCC, Miranda MS, et al. Manejo do trauma de coluna cervical em pacientes politraumatizados. Rev Méd Minas Gerais [Internet]. 2009 [citado em $23 \mathrm{dez}$ 2021]; 19(2 Supl. 3):130-35. Disponível em: http://rmmg.org/artigo/detalhes/1226 17. Sistema Único de Saúde, Serviço de Atendimento Móvel de Urgência, Núcleo de educação permanente SAMU 192 
(Porto Alegre). Manual de primeiros socorros para leigos [Internet]. Porto Alegre: SAMU; 2013 [citado em $23 \mathrm{dez}$ 2021]. 42 p. Disponível em:

http://lproweb.procempa.com.br/pmpa/pref poa/sma/usu_doc/samu.pdf 18. Brolezi EA. Orientações de primeiros socorros em urgência na escola. Saúde Foco [Internet]. 2014 [citado em 08 jun 2019]; 111-23. Disponível em: https://portal.unisepe.com.br/unifia/wpcontent/uploads/sites/10001/2018/06/15pri meiros_socorros_naescola.pdf

RECEBIDO: $13 / 07 / 2020$

APROVADO: 09/08/2021

PUBLICADO: dez/2021 